https://doi.org/10.48009/1_iis_2010_77-84

\title{
SOFTWARE DEVELOPMENT AND INTELLECTUAL PROPERTY: WHAT YOU DON'T KNOW CAN HURT YOU
}

\author{
Janet Ford, Western Carolina University, ford@email.wcu.edu \\ Barbara Jo White, Western Carolina University, whiteb@email.wcu.edu \\ Lorrie Willey, Western Carolina University, willey@email.wcu.edu
}

\begin{abstract}
CIOs face increasing risks when they lack fundamental awareness of laws impacting information system activities. For anyone involved in software development, a basic knowledge of intellectual property, specifically patent and copyright law, is a must. The need is two-fold: first to protect innovations and inventions and second, to gain a competitive advantage. This paper provides an overview of statutory law on intellectual property as well as the significant federal cases interpreting these statutes as they apply to software development.
\end{abstract}

Keywords: Intellectual Property, Software Development Life Cycle, Legal Issues in Information Technology

\section{INTRODUCTION}

Intellectual Property (IP) has a significant economic impact on technology firms. Licensing IP rights can generate substantial revenue while infringing IP rights can result in costly drawn-out legal battles. IBM illustrates the revenue-generating possibilities of IP. For example, in one ten-year period (from 19932004), IBM recorded over 22,357 patents that contributed to $\$ 10$ billion in IP licensing revenues, for both copyrighted and patented material [60]. On the other hand, Microsoft's protracted court battle with Apple has generated millions in legal fees and court costs for both firms.

Anyone aspiring to succeed in the IT industry, from students to CIOs, needs a basic understanding of major issues in intellectual property law. Copyrights and patents serve as the cornerstone of IP law.

While small firms and entrepreneurs might depend on searching intellectual property databases (such as www.copyright.gov for copyrights and www.uspto.gov for patents) to see if their ideas aren't as original as they hoped, large firms have more sophisticated solutions. In fact, IBM, which has developed IP management software that provides analytical, assessment and administrative capabilities, recently announced that it would begin marketing its IP management software to external firms [51]. Other firms could integrate an awareness of intellectual property in the different stages of the software development life cycle in what is referred to as the "Patent-Based Software Life Cycle" [43]. Such an approach protects software developers from inadvertently infringing upon the rights of patent holders and also prompts developers to recognize and take advantage of patent opportunities.

Generally, the software development lifecycle proceeds through the typical stages of analysis (requirements gathering), design, implementation, testing and maintenance. A more patent-aware software development life cycle (SDLC) approach includes validating and verifying existing patents at each stage in the life cycle. This is essentially a defensive IP approach. A more offensive IP approach includes applying for patents at each stage of the SDLC [43].

This type of patent-based SDLC can contribute to a patent portfolio that can be quite a valuable asset for a firm. Four stages Gartner analyst Brian Prentice identified that firms go through when they leverage their patent portfolios include: Patent Victim, the stage in which a firm is attacked regularly; Defensive Patentee, the stage in which the target firm develops its patent portfolio as part of its IP strategy in order to defend against attacks; License Experimenter, the stage in which the target firm explores ways to leverage its patent portfolio and proactively protect its interests; and Offensive Patentee, the stage in which target firms actively exploit their patent portfolios through cross-licensing and other license revenue generating measures [58].

Generating IP revenues and reducing IP-related costs begins with an understanding of IP law. This paper provides a broad overview of the statutory law regarding copyrights and patents, as well as the significant federal cases interpreting these statutes as they apply to software. An understanding of the statutes and their interpretation provides a foundation for understanding the legal concerns associated with the protection of software programs. 


\section{Intellectual Property Protection: Software/Programs}

The ultimate legal authority for the protection of intellectual property in the United States resides in the United States Constitution. Congress is vested with the power "to promote the progress of science and useful arts, by securing for limited times to authors and inventors the exclusive right to their respective writings and discoveries [65]." Congress has exercised its authority in this area by enacting and frequently amending comprehensive legislation addressing the two main areas of intellectual property protection: copyright and patent. Broadly speaking, copyright law covers the "useful arts" and patent covers the "science" referred to in the constitutional mandate, although the two areas may occasionally overlap - especially in the area of computer programming and software development.

\section{LEGAL ISSUES AND COPYRIGHTS}

Developments in software have triggered legal disputes over whether certain aspects of a software program are subject to copyright. For example, can the developer of an application claim a copyright for the intuitive icons for "home" or "cut" or "refresh"? Does a specific code sequence in a program represent a non-copyrightable idea or is it a copyrightable expression of an idea? Answering these and other questions requires reference first to the statutory law of copyright and, where that source does not provide a clear answer, further inquiry into whether and how courts have resolved the issue.

\section{Copyright Law: The Statutory Scheme}

Section 102 of Title 17 extends copyright protection to "original works of authorship fixed in any tangible medium of expression, now known or later developed, from which they can be perceived, reproduced, or otherwise communicated, either directly or with the aid of a machine or device [1]." The statute provides a non-exhaustive list of works that may be copyrighted: literary works, musical works, including lyrics, dramatic works along with any accompanying music, choreography, visual art, recorded pictures and sounds, and architectural works [1]. Specifically excluded from copyright protection is "any idea, procedure, process, system, method of operation, concept, principle, or discovery, regardless of the form in which it is described, explained, illustrated, or embodied. . . [2]." These items are protected by patent laws, which will be addressed below.

Volume XI, No. 1, 2010
Once an original work has been "fixed in a tangible medium of expression" its author, as the default owner of the copyright, enjoys numerous exclusive rights as to that work. If the work was created pursuant to an employment agreement or some other written agreement, it is considered a work made for hire, and the employer or party who commissioned the work is the copyright owner [5]. Copyright protection therefore exists as soon as the original work is created and "fixed in a tangible medium of expression" - no publication or other formalities need occur for the copyright to become effective. The exclusive rights that copyright owners possess include the right to reproduce the work, prepare derivative works based upon the copyrighted work, distribute copies of the work to the public, and publicly perform, display, or digitally transmit the work [3]. These rights, in whole or in part, may be sold, transferred, assigned, bequeathed, or otherwise voluntarily conveyed to others [6]. In some bankruptcy situations, these rights may be involuntarily conveyed to others [7].

To determine how long copyright protection for a certain work lasts one must know the date of its creation. The last major overhaul of American copyright law, the Copyright Act of 1976, represented just one of many alterations of the duration of copyright protection. Currently, for works created on or after January 1, 1978, the standard duration of copyright protection is the life of the author plus 70 years [8]. In the case of a work for hire, the term is either 95 years after its first publication or 120 years after its creation, whichever is shortest [9]. Works that were created before January 1, 1978 but not published or copyrighted under the law as it then existed are protected for the same terms set out in Section 302 [10]. Prior to January 1, 1978, copyright protection secured pursuant to existing law could be renewed. Section 304 of Title 17 contains detailed provisions addressing the copyright protection for works that were either in an initial copyright term or in a renewal term under prior law.

The author of a copyrighted work may, but is not required to, provide notice of the copyright on his original work. Notice of copyright may take one of three forms described by statute: (C) 2010 John Doe; copyright 2010 John Doe; or copr. 2010 John Doe [12]. Likewise, registration of a copyright with the federal Copyright Office is permitted, even encouraged, but not required in order for copyright protection to exist [13]. Copyright registration is required, however, before an owner of the copyright may initiate litigation for its infringement [14]. 
Registration of copyright requires submission of an application, copies of the work to be registered, applicable fees, and any other information necessary for the Register of Copyright to determine whether the work is copyrightable. The federal Copyright Office maintains a website with the necessary information, instructions, and forms to facilitate registration, and applications for registration may be submitted online.

Copyright law defines infringement of copyright as the violation of the exclusive rights identified in Sections 106 through 122 of Title 17 of the United States Code. Anyone can be held responsible as an infringer, including state agencies, instrumentalities, officers, or employees [15]. If the court finds that the copyright has been infringed, it may order various forms of relief to the copyright owner. The court may issue an injunction forbidding continued infringement of the copyright, and any such injunction will be recognized and enforced throughout the United States [16]. Additionally, the court may order that all infringing items be taken into the custody of the court and destroyed or otherwise appropriately disposed of [17]. The court may also award monetary damages measured by either the owner's loss, the infringer's profit, or a combination of the two. Alternatively, an owner may choose to accept a statutorily defined amount of damages, which may be enhanced if the owner can prove that the infringer acted willfully in violating the copyright [18]. Regardless of who wins a copyright infringement suit, the court may, in its discretion, order either side to pay the other party's court costs, and may order the losing party to pay the winning party's attorney's fees [19]. In addition to these civil remedies, courts may also impose criminal sanctions for willful copyright infringement under certain circumstances [20].

In copyright infringement lawsuits, perhaps the most prominent defense to infringement allegations is known as the Fair Use Doctrine. Under this doctrine, the unauthorized copying, use, or distribution of a copyrighted item is not an infringement if the purpose of that unauthorized use is for "criticism, comment, news reporting, teaching (including multiple copies for classroom use), scholarship, or research [4]." To determine if an alleged infringement falls within a fair use of copyrighted material, courts analyze four factors, none of which is determinative. Those factors are: "(1) the purpose and character of the use, including whether such use is of a commercial nature or is for nonprofit educational purposes; (2) the nature of the copyrighted work; (3) the amount and substantiality of the portion used in relation to the copyrighted work as a whole; and (4) the effect of the use upon the potential market for or value of the copyrighted work [4]." An alleged infringer will not be held liable for copyright infringement if the court finds that his actions constituted a fair use of the copyrighted material.

In addition to the Fair Use Doctrine, Title 17 contains certain other statutory defenses to copyright infringement in the field of technology and computers. Section 117 allows someone who has lawfully acquired an authorized copy of a computer program to make an archival, or "backup," copy of that program for limited purposes. Section 512 protects service providers from infringement liability where third parties have used the service provider's network to produce, store, or transmit unauthorized copies of protected materials.

Copyright law has been amended frequently in an attempt to address new issues raised by emerging technology and developments in society. For example, Section 101 was amended in 1980 to add the definition of a computer program to the list of terms frequently encountered in Title 17. The Copyright Act of 1976 was further amended in 1984 to provide protection for the design of semiconductor chips, which amendments were then amended further to address protection for the semiconductor chip products of foreign entities [21]. The rise in popularity first of videocassette recorders and then a wider variety of recording devices and techniques led to the Audio Home Recording Act of 1992 [22]. The rapid pace of technology designed to protect against unauthorized copying or distribution of protected materials and the equally rapid pace of technology designed to thwart those protective measures prompted Congress to enact the Digital Millennium Copyright Act of 1998. In addition to allowing certain backup copies of protected software in Section 117 and protecting service providers from liability for the acts of third parties under Section 512, this 1998 act, among other things, prohibits attempts to circumvent copyright protection systems [23]. The expanding use of online and distance education approaches to content delivery by educational institutions prompted the Technology, Education, and Copyright Harmonization Act of 2002 ("TEACH" Act), located in Section 110 of Title 17, which allows such institutions to reproduce and distribute protected material in a manner that could otherwise lead to an infringement action.

It is readily apparent that the legislative response to the rapidly changing world of technology has, from a copyright standpoint, been piecemeal, incomplete, 
and slow. Increasingly, developers and users of technology have been turning to the courts to resolve the myriad intellectual property issues left unanswered by copyright law. To further confuse matters, the lower federal courts have not been unanimous in their approaches to emerging issues in intellectual property law. Consequently, the public must wait for definitive guidance until either the United States Supreme Court or Congress weighs in on an issue.

\section{Copyright Case Review: Ideas and the Expression of Ideas in Software Development}

Court analysis of software cases often reflects the need to review specific aspects of software programs to determine whether the program, or portion of the program, can be protected. The following cases serve to illustrate the nature of this review. Authorship of a software program generally is not a difficult requirement to meet for copyright protection. As literary works, source code is, in fact, written by an author. In 1983, a court addressed whether the program's object code, specifically an operating system embedded in ROM, qualified for copyright protection. Since object code was an integral component in the computer's ability to use written source code and since the object code was embedded in ROM, the answer in this instance was yes [40]. To add clarity to the issue of copyright protection for programs, Congress amended the Copyright Act in 1980 to specifically include programs, a mandate courts felt to be receptive to new technology [40]. With the requirements of authorship and fixed medium resolved, courts now turned to the more difficult distinction between a non-copyrightable idea and the copyrightable expression of an idea.

In 1986, the U.S. Court of Appeals considered the copyright protection afforded a program's structure. While earlier courts identified source code and object code as the basis of copyright protection, this Court considered whether the overall structure of a program was protected under copyright law. Those aspects of a program that are expressive elements of ideas are copyrightable while the actual ideas are not. The program in question was developed to perform record-keeping functions for a dental laboratory. It was developed with Event Definition Language (EDL) as the source code language and subsequently, another author developed a program, based on the EDL program, in BASIC. The owner of the BASIC program did not challenge the developer's ownership of the EDL program, but argued that the structure was an idea and therefore, not subject to copyright. The Court considered the overall function of the program, in this case, the maintenance of dental laboratory records, as the idea and the structure of the specific program as the required expression of the idea, a non-literal copyrightable expression [64].

The "idea-expression distinction" became an elaborate consideration of the copyright protection for menu command structures, command terms and their structure, screen presentation and long prompts. Were those features just ideas or did they constitute expressions of ideas? The answer was that since command structure can be expressed in many different ways, the particular structure in question was more than just an idea; it is the expressed idea [55]. However, this approach was not followed in all federal courts.

In a later case, a programmer copied $30 \%$ of the code he developed for a previous employer into a similar program for a new employer. Once the second employer learned of the copying, a rewrite of the program was executed in an attempt to eliminate the infringed code. The question for the court was whether the newly-written program, while containing different code, infringed on the non-literal aspects of the original program. The court relied on an abstraction filtration comparison of the two programs. Such an analysis hinges on factual determinations made during several analytical steps: breaking down the program into its structural parts (abstraction); examining each part for ideas, expressions of ideas and ideas taken from the public domain (filtration) ; and finally, comparing the components that compose the structure of one program to those of another. Using this test, the court found there was no infringement [48]. In essence, creative expressions of ideas could be separated by those aspects of the program that were functional and, therefore, not subject to copyright protection.

Access to and an understanding of the functional aspects of a program was the basis for a discussion of the fair use exception to the protections afforded by a copyright. A game manufacturer copied code from a competitor in order to pull out the functional aspects of the code which would enable it to develop compatible games for the competitor's product. Here, the disassembling and copying of the competitor's code was necessary in order to get to the functional and non-protected components and was, therefore, permitted. "It is ...this growth in creative expression, based on the dissemination of other creative works...that the Copyright Act was intended to promote [61]." 
However, the look and feel of a program was held not to be protected under copyright law. In this instance Apple sued Microsoft for copyright infringement of Apple's desktop window and visual interface. Microsoft and many other competitors used the desktop concept and similar visuals in their desktop interfaces. The court determined that the components that created the look and feel of a program were, in fact, ideas and not the expression of ideas. As such, these ideas were not subject to protection. In part, the court relied on the theories that that copyright law must not be so inclusive as to inhibit standardization of interface components and that items purely functional are not protected [41].

\section{LEGAL ISSUES AND PATENTS}

In addition to copyright concerns, technology firms also resort to patents as a means of protecting innovation. For the last 17 years, IBM has obtained more patents than any other US firm; in 2009, IBM had 4914 patents [54]. As with copyright, an understanding of current patent law, both statutory and court-driven, as well as unresolved issues in patent law is beneficial to technology firms, employees, and students.

\section{Patent Law: The Statutory Scheme}

Section 101 of Title 35 of the United States Code states that a patent may be awarded to "[a]nyone who invents or discovers any new and useful process, machine, manufacture, or composition of matter, or any new and useful improvement thereof [24]." The invention or discovery must be something novel, not something previously "known or used by others," either in the United States or abroad [25]. Even a novel invention or discovery might not be eligible for patent if it represents a development of a "prior art" that would be "obvious . . . to a person having ordinary skill in the art to which said subject matter pertains [26]." Additionally, the United States Supreme Court has followed the common law tradition of denying patent protection to laws of nature, physical phenomena, and abstract ideas [46]. Under this approach, "a new mineral discovered in the earth or a new plant found in the wild is not patentable subject matter. Likewise, Einstein could not patent his celebrated law that $\mathrm{E}=\mathrm{mc}^{2}$; nor could Newton have patented the law of gravity [49]." Denial of patent protection to natural phenomena strikes a balance between the competing goals of patent law, which are to provide economic incentives for research and invention without unduly restricting the free flow of information.
To obtain a patent, an inventor must submit an application to the United States Patent and Trademark Office ("PTO"). The application must include: (1) a detailed written description of the invention and the means by which it was created and is used and also a claim specifically identifying what the inventor considers to be his invention; (2) drawings to illustrate or explain the invention or in some cases a model or specimen of the invention; (3) a statement by the inventor given under oath attesting to a good faith belief that the inventor is the first person to invent the device or process, along with a statement of national citizenship; and (4) statutory fees [27]. Subject to certain exceptions, patent applications are to be published 18 months after the application is filed, unless the applicant certifies that he will not seek patent protection outside of the United States [28]. If, following an examination of the application the PTO rejects the application, the applicant has the right to seek re-examination of his application, and if the application is again rejected the applicant may appeal to the Board of Patent Appeals and Interferences. Similarly, a third party who is opposed to the issuance of a patent may appeal the grant of a patent to the Board of Patent Appeals and Interferences [29]. In turn, any party dissatisfied with the final decision of the Board of Patent Appeals and Interferences may appeal that decision in the Court of Appeals for the Federal Circuit [30]. Alternatively, a rejected applicant may file a civil action against the Director of the PTO in the federal District Court for the District of Columbia [31]. The United States Supreme Court may, in its discretion, review a decision from the Court of Appeals [63].

If, after examination of the patent application, the PTO determines that the applicant is entitled to a patent, the applicant will be notified of the allowance and of the issue fee that must be paid before the patent will be issued. The applicant has three months following the notice of allowance to pay the issue fee, or else the patent application will be considered abandoned [32]. Once the patent has been issued, the patentee, as the successful applicant is now called, enjoys the exclusive right to make, use, or sell the invention in the United States or import that invention into the United States. If the patent covers a process, the patentee has the exclusive right to use, offer, or sell in, or import into, the United States any products made by that process [33]. Patent protection begins on the date that the patent issues and ends 20 years from the date of the application [34]. Administrative delays in the application examination and appeals processes may in some circumstances justify extensions of the protection period [35]. An 
extension of the patent protection term may also be granted where the subject matter of the patent application was a substance or process subject to review and regulation by the Federal Food and Drug Administration [36]. A patent is considered personal property, and may be conveyed through an assignment of the patent in writing. An assignment of a patent must be recorded in PTO [37].

Unauthorized making, using, or selling a patented invention in the United States or the importation thereof into the United States constitutes an infringement of the patent. Infringement also occurs when one makes, uses, sells in, or imports into, the United States products made from a patented process [38]. Upon establishing that an infringement has occurred or is occurring, a patentee is entitled to injunctive relief as well as monetary damages. Regardless who wins a patent infringement lawsuit, that prevailing party may, in exceptional cases, be awarded attorney's fees [39].

\section{Patent Case Review: Algorithms, Natural Law and Transformation}

Cases involving programs, and the algorithms that support them, have long posed particular concern for courts determining a program's patentability. The following cases demonstrate a historical review of the legal analysis associated with the patent eligibility of software programs. Until the 1980 s, courts took a somewhat limited view of a program as a process utilizing algorithms. As "basic tools of scientific and technological work [51]," algorithms were merely mathematical formulas constituting laws of nature and, therefore, ineligible for patent protections. After considering the patent eligibility of a program developed to convert binary-coded numerals into binary numbers, the U. S. Supreme Court determined the program had no function other than in a digital computer, that is, the program did not alter the function of the computer [51].

A short time later, the Court heard another appeal involving a program that updated alarm limits during a catalytic conversion process. At the time, a system already existed for the establishment of such limits; the method before the Court just included an additional algorithm that adjusted the alarm limits through the program. The Court looked for, and did not find, activity beyond the algorithm that would transform the process into something novel and unique and so determined the program ineligible for patent protection [56].
However, the required transformation was found in an analysis of a patent application for a program that monitored and adjusted temperatures during a rubber molding process. In basic terms, the program monitored the temperature of curing rubber in real time and then sent messages to the device to adjust the temperature of the process. Ultimately, the result was a machine that created properly molded and cured rubber. This program was not just a mathematical abstraction; it actually represented a process, involving several steps that created the desired result. The algorithm employed was one step of the process but allowing the patent for the process did not impede the use of that algorithm by others [50].

Transformation became an integral part of considering the patentability of programs. The use of mathematical formulas that allowed a machine to convert heartbeats into readable signals on a display, transformed the algorithm into a physical process which converted one electrical signal into another. Ultimately, a useful and tangible thing, a reading of a patient's heartbeat, resulted that was protected by patent law [42]. The "useful, concrete, and tangible result" as a determinant factor in patent cases applied to algorithms in various processes. Later, this factor would come into disfavor as a means to determine eligibility [53].

Until then though, the "useful, concrete, and tangible result [62]" consideration was also applied to a business process that transformed data into dollar amounts by means of mathematical formulas. Although the process was, in actuality, a series of mathematical algorithms, the fixing, if even momentarily, of a final share price made the process eligible for patent protection. This case established the concept that business processes could be patented if all requirements were met and they also produced a useful, concrete and tangible result [62]. The floodgates for applications for patents on business processes were open.

Transformation of a machine was the foundation of a 1994 case involving the invention of a program to enhance the waveform display of an oscilloscope. Although the program involved a mathematical algorithm, the court decision was focused on the invention as a machine rather than as a program. The mathematical formula involved in this invention did not stand alone; it served to combine elements into a machine that produced a "useful, concrete, and tangible result [52]." In essence, the program transformed a computer into a machine and established means and function [52]. What now is the 
actual test for the patent eligibility of processes? Is a transformation of the algorithms into a machine or the transformation of materials into a different state or thing required? Is a useful, concrete and tangible result sufficient?

In re Bilski, involved a business process developed by Bernard Bilski and Rand Warsaw for hedging risk in the commodities market. The Patent and Trademark Office denied the patent application. On appeal, the Court of Appeals established what it believed had always been required of processes in order to obtain a patent; that the process is tied to and transforms a machine or the process transforms an article into something else. While "[t]he raw materials of many information age processes, however, are electronic signals and electronically manipulated data," as they were for the process developed in this case, the Court held that the process in question did not "transform any article to a different state or thing [53]." The Court of Appeals specifically rejected the "useful, concrete and tangible result" standard as a factor for determining eligibility for a patent [53]. The Court of Appeals decision was appealed to the United States Supreme Court.

In its recently released Bilski opinion, the Supreme Court did little to definitively resolve the questions involving the patent eligibility of programs in the form of business processes. Rather than directly addressing the question of process patentability, the Court determined that the Bilski process was ineligible for patent protection because the applicant was attempting to gain a patent for an "abstract hedging idea" [45]. "The patent application here can be rejected under our precedents on the unpatentability of abstract ideas" and the Court refused to further clarify the nature of a patentable process [46]. The Court did, however, note that the machine or transformation test was not the "exclusive test" for the eligibility of processes for patent protection [47].

\section{CONCLUSIONS}

Over the past four decades, the courts have been struggling to determine the extent of copyright and patent protection afforded software programs or business processes. Statutory law defines the parameters of eligibility and protection, but software programs create a unique consideration in the judicial interpretation of statutes.

Copyright is easier and cheaper to obtain, and the protection lasts longer. Regarding computer software, the main copyright issue appears to be the distinction between a non-copyrightable idea and copyrightable expressions of ideas. A software developer who generates a novel idea cannot protect that idea from being used by competitors; he can only prevent competitors from using his unique expression of that idea. Another drawback to copyright protection is the notion that competitors can decompile software programs and then claim the Fair Use defense. Also, copyright laws do not inquire into the merit or usefulness of an original work of authorship

The patent application process, by contrast, is more demanding than the copyright process in several respects. A patent applicant must affirmatively establish his claim to be the first to invent a machine or process and must disclose information that might render the invention unpatentable. Moreover, inventions are subjected to a rigorous examination by specialists in the subject matter to determine if the invention is truly novel, nonobvious, and not a natural phenomenon. The patent application process permits intervention by third parties who have an interest in defeating the application. The complexity of the patent application process often requires expensive specialists, from legal experts in intellectual property to experts in the subject matter of an invention.

Once an applicant has run the application gauntlet and received a patent, the patentee enjoys a much shorter period of protection for the invention compared to a copyright holder. However, patent law does not contain the very broad Fair Use defense that is available under copyright law, and patent protection is arguably more comprehensive. The potentially lucrative financial rewards of a patent often motivate inventors to undertake the application process. Technology firms need to consider how intellectual property laws can impact their bottom lines and develop IP strategies to mitigate risks and take advantage of opportunities.

\section{REFERENCES}

1. 17 U.S.C. $\S 102(a)$

2. 17 U.S.C. $\$ 102$ (b)

3. 17 U.S.C. $\$ 106$

4. 17 U.S.C. $\$ 107$

5. 17 U.S.C. $\S 201$

6. 17 U.S.C. $\$ 201(d)$

7. 17 U.S.C. $\$ 201(\mathrm{e})$

8. 17 U.S.C. $\$ 302(a)$

9. 17 U.S.C. $\$ 302(c)$

10. 17 U.S.C. $\S 303$ 
11. 17 U.S.C. $\$ 304$

12. 17 U.S.C. $\$ 401$

13. 17 U.S.C. $\$ 408(a)$

14. 17 U.S.C. $\$ 411(\mathrm{a})$

15. 17 U.S.C. $\S 501$

16. 17 U.S.C. $\$ 502$

17. 17 U.S.C. $\$ 503$

18. 17 U.S.C. $\$ 504$

19. 17 U.S.C. $\$ 505$

20. 17 U.S.C. $\$ 506$

21. 17 U.S.C. $\$ \$ 901-914$

22. 17 U.S.C. $\S \S 1001-1010$

23. 17 U.S.C. $\S \S 1201-1205$

24. 35 U.S.C. $\$ 101$

25. 35 U.S.C. $\S 102$

26. 35 U.S.C. $\$ 103$

27. 35 U.S.C. $\$ \S 111-115$

28. 35 U.S.C. $\$ 122$

29. 35 U.S.C. $\$ \S 132,134$

30. 35 U.S.C. $\$ 141$

31. 35 U.S.C. $\$ 145$

32. 35 U.S.C. $\$ 151$

33. 35 U.S.C. $\S 151(a)(1)$

34. 35 U.S.C. $\S 151(\mathrm{a})(2)$

35. 35 U.S.C. $\$ 154(b)$

36. 35 U.S.C. $\$ 155$

37. 35 U.S.C. $\$ 261$

38. 35 U.S.C. $\$ 271$

39. 35 U.S.C. $\S \S 283-285$

40. Apple Computer Inc. v. Franklin Computer, 714 F. 2d 1240 (4th Cir. 1983).

41. Apple Computer Inc. v. Microsoft Corporation, 799 F. Supp. 1006 (N.D. Cal. 1992)

42. Arrhythmia Research v. Corazonix Corp., 958 F. 2d 1053 (Fed. Cir. 1992).

43. Bergstra, JA. \& Klint, P. (2006). About "trivial" software patents: The IsNot case. Science of Computer Programming, 64(\#), 264-285.

44. Bilski and Warsaw v. Kappos, 129 S. Ct. 2735 (2009).

45. Bilski v. Kappos, 561 U.S. opinion at page 4.

46. Id., at page 20 .

47. Id., at page 11 .

48. Computer Associates International v. Altai Inc., 1992 WL 139364 (E.D.N.Y. 1992).

49. Diamond v. Chakrabarty, 447 U.S. 303, 309 (1980).

50. Diamond v. Diehr (1922). United States Supreme Court, 450 U.S. 175.

51. Gottshalk v. Benson, 409 U.S. 63 (1992).

52. In re Alappat, 33 F. 3d 1526 (3rd Cir. 1994).

53. In re Bilski and Warsaw, 545 F. 3d 943 (Fed. Cir. 2008).

54. IBM (January 12, 2010). IBM Earns Most U.S. Patents for 17th Consecutive Year; Will Offer
Licenses to Patent Portfolio Management KnowHow. Press Release, Available: http://www03.ibm.com/press/us/en/pressrelease/29168.wss

55. Lotus Development Corporation v. Paperback Software International, 740 F. Supp. 37 (D.C. Mass. 1990).

56. Parker v. Flook, 437 U.S. 584 (1978).

57. Prentice, B. (February 10, 2010). End users become an opportunity for technology providers' patent portfolios. Gartner, Inc., Available: http://my.gartner.com/portal/server.pt?open=512 \&objID $=260 \&$ mode $=2 \&$ PageID $=3460702 \&$ doc Code $=173729 \&$ ref $=$ docDisplay

58. Prentice, B. (March 5, 2009). Microsoft accelerates a trend by flexing its patent muscle. Gartner, Inc., Available:

http://my.gartner.com/portal/server.pt?open=512 \&objID $=260 \&$ mode $=2 \&$ PageID $=3460702 \&$ doc Code $=166050 \&$ ref $=$ docDisplay

59. Prentice, B. (2008). Vital issues for the evolving intellectual property landscape, 2008. Gartner, Inc., Available:

http://my.gartner.com/portal/server.pt?open=512 \&objID $=260 \&$ mode $=2 \&$ PageID $=3460702 \&$ doc Code $=161001 \&$ ref $=$ docDisplay

60. Radjou, N. (March 24, 2005). IBM Transforms its Supply Chain to Drive Growth. Forrester Research, Inc., Available: http://www935.ibm.com/services/us/gbs/bus/pdf/ibmtransforms-supply-chain-to-drive.pdf

61. Sega Enterprises Ltd. V. Accolade, Inc., 977 F. 2d 1510 (9th Cir. 1992).

62. State Street Bank and Trust Co. v. Signature Financial Group Inc., 149 F. 3d 1368 (Fed. Cir. 1998).

63. Supreme Court Rule 10, 2010.

64. Whelan Associates v. Jaslow Dental Laboratory Inc., 797 F. 2d 1222 (3rd Cir. 1986).

65. U.S. Constitution, art. I, $\S 8$ 